\title{
Mercury Concentration Testing in Local Fish Populations in Anguilla with Correlations of Potential Complications Related to Long Term Mercury Ingestion in Caribbean Populations
}

\author{
Samith Ahmed ${ }^{1}$, Samira Abdul Wajid², Sean Donohue ${ }^{3}$, Rachel Pennington ${ }^{4}$, Samuel Pesch ${ }^{5}$, Natalie Russell ${ }^{6}$
}

1Department of Pathology, Saint James School of Medicine, Anguilla, British West Indies. 2Department of Microbiology, Saint

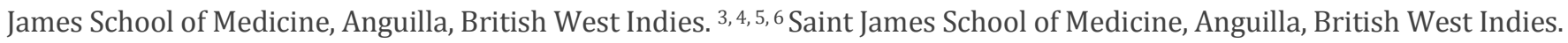

\section{ABSTRACT}

\section{BACKGROUND}

Mercury is a common element found in household, industrial and medical products. Mercury waste has the potential to leak into rivers that flow to the oceans where bacteria can convert mercury into a soluble form that can allow concentrations to build up in local fish populations. Previous research performed in Anguilla in 2013 2014 found that the fish species Mahi mahi had the highest mercury concentration at $0.08 \mathrm{mg} / \mathrm{Kg}$. The FDA and WHO recommend a maximum of $1 \mathrm{mg} / \mathrm{Kg}$ per year. Chronic ingestion of mercury has been linked to pregnancy complications, early childhood developmental complications, and various neurological and gastrointestinal manifestations.

\section{METHODS}

Fish tissue samples were acquired locally on the Caribbean Island of Anguilla from 10 different fish species, documented, prepared for temporary preservation and sent to the Biodiversity Research Institute where mercury concentration processing was performed on their DMA (Direct Mercury Analyzer).

\section{RESULTS}

Data showed that mercury concentrations have risen for certain fish species and fallen in others since samples were last taken in 2013. The mercury concentration of Mahi mahi decreased, back in 2013 the reported concentration was $0.08 \mathrm{mg} / \mathrm{Kg}$ while the 2020 result was $0.023 \mathrm{mg} / \mathrm{Kg}$. On the other end of the spectrum, the mercury concentration of the Red Hind species in 2013 was $0.07 \mathrm{mg} / \mathrm{Kg}$ and had increased to $0.2604 \mathrm{mg} / \mathrm{Kg}$ in 2020.

\section{CONCLUSIONS}

Our findings support the notion that mercury concentrations within the tissues of fish around the Caribbean island of Anguilla have increased. Future mercury testing should be performed around other local Caribbean islands so as to compare the relative mercury concentrations and so that local governments can also appropriately inform the Caribbean communities of the potential risks they take with chronic ingestion of local seafood.

\section{KEY WORDS}

Anguilla, Methyl Mercury, Direct Mercury Analyzer, Red Snapper, Yellow Tail Snapper, Red Hind, Triggerfish, White Back Bar Jack, Doctor Fish, Mahi mahi, Grunt Fish, Alzheimer's Disease (AD), Direct Mercury Analyzer (DMA), Method Detection Limit (MDL), Parts Per Million (ppm), Instrument Detection Limit (IDL)

\author{
Corresponding Author: \\ Dr. Samith Ahmed, \\ Associate Professor, \\ Department of Pathology, \\ Saint James School of Medicine, \\ Albert Lake Drive, \\ The Quarter, The Valley, \\ Anguilla A-1 2640, \\ E-mail: samith_17@yahoo.com
}

DOI: $10.14260 /$ jemds/2020/684

How to Cite This Article:

Ahmed S, Wajid SA, Donohue S, et al. Mercury concentration testing in local fish populations in anguilla with correlations of potential complications related to long term mercury ingestion in caribbean populations. J Evolution Med Dent Sci 2020;9(42):3117-3121, DOI: 10.14260/jemds/2020/684

Submission 09-07-2020,

Peer Review 12-09-2020,

Acceptance 19-09-2020,

Published 19-10-2020.

Copyright (C) 2020 Samith Ahmed et al. This is an open access article distributed under Creative Commons Attribution License [Attribution 4.0 International (CC BY 4.0)] 


\section{BACKGROUND}

Mercury is a very useful element and is found in many household, industrial, and medical products. Although useful, mercury is also very harmful to humans as it is a major environmental pollutant that is toxic and is never fully destroyed. Mercury exists in three different forms, which differ in regards to intensity of toxicities, and ultimately, the effect they have on the Central Nervous System (CNS) and other organ systems of the human body. Elemental or metallic mercury $(\mathrm{Hg}$ ) can be found in thermometers and fluorescent light bulbs. It is liquid at room temperature and is evaporated into the atmosphere as mercury vapours. Inorganic mercury compositions are formed when mercury reacts in the atmosphere with oxygen and sulphur. Lastly, organic mercury is formed when inorganic mercury is released from various contaminants on land into the water ecosystems, and combines with carbon to produce methylmercury. This process is accelerated by bacteria and plankton in the water which increase this toxic transformation through bioaccumulation, as methylmercury concentrations increase with each step of the food pyramid. ${ }^{1}$

The main origin of methylmercury in the humans comes from ingested seafood, as they naturally store high concentrations within their organs once ingested. ${ }^{2}$ Methylmercury is proven to be a potent neurotoxin that can cause dysfunction. In particular, The U.S. Environmental Protection Agency (EPA) reported that the foetuses of pregnant women are said to be at an increased risk for mercury poisoning due to methylmercury being able to cross the placenta and disrupt the normal development of cognitive thinking, language, memory, and fine motor skills. ${ }^{3}$ Another population at an increased risk are those who are regularly exposed to mercury concentrations, including those who consume high amounts of seafood in their diet. Fish and seafood are a main source of protein in the diets of many individuals all over the world. Fish contain omega-3 fatty acids, specifically eicosapentaenoic acid (EPA), and docosahexaenoic acid (DHA). According to the National Institute of Health (NIH), these have been scientifically proven to prevent development of chronic diseases including Alzheimer's and dementia (cognitive function), rheumatoid arthritis, cardiovascular disease, and infant health and development. ${ }^{4}$ However, while fish have their many health advantages, some species in particular may contain higher concentrations of mercury than others, which could be dangerous to human health. This criterion has been based on several components like their trophic level in the food pyramid, dimensions and weight of the fish, as well as habitat location.

A research study conducted by the Department of Marine Biology at the University of Texas tested the bioaccumulation of mercury in pelagic fish in the North West Gulf of Mexico, and its relationship with length, location, collection year, and trophic level. Results showed a positive relationship between total mercury concentration and size of fish, as well as a positive exponential relationship between mercury concentration and trophic position. The blue marlin showed to contain the highest concentration of mercury, potentially due to their long life span and large size, thus allowing more mercury to accumulate. 5 Another study that examined mercury quantities in oceanic fish that were commonly ingested around Peninsular Malaysia concluded that total mercury quantities in those particular oceanic fish was positively correlated with length and weight. Higher concentrations of mercury were also found in carnivorous fish species compared to herbivorous fish species. Finally, the study showed that fish caught in regions with high pollutant input from manufacturing and cargo ship transport of goods had notably increased mercury concentrations than fish in less industrialized habitats. ${ }^{6}$ The United States is a country in close proximity to the Caribbean. The average US citizen in 2017 consumed 16 pounds $\left(7.25 \mathrm{Kg}\right.$ ) of sea food. ${ }^{7}$ In the Caribbean, the average annual fish consumption is $14.1 \mathrm{Kg}$ per capita. ${ }^{8}$ This is nearly a $48 \%$ increase in seafood consumption in the Caribbean compared with its neighbour, the United States, per year.

Previous research, performed by Saint James School of Medicine students in 2013 - 2014, found the highest mercury concentration within the fish species surrounding Anguilla were Mahi mahi, which contained about $0.08 \mu \mathrm{g}$ in Anguilla with recommendations of performing experimental research again in the near future. ${ }^{9}$ The Food and Drug Administration (FDA) and World Health Organization (WHO) recommend a maximum of $1 \mu \mathrm{g}$ mercury ingestion per year. The Biodiversity Research Institute, United States Environmental Protection Agency (EPA), the United States FDA, and the Great Lakes Consortium of the United States / Canada all recommend a limit of 1 meal per week of the fish species, Mahi mahi, with a serving size of 4 ounces due to potential low-level mercury toxicity. ${ }^{10}$ As of today, no research on seafood mercury levels has been done in the island of Anguilla since this study. The main goal and objective of this study is to test the current levels of mercury in local fish caught around the Caribbean island of Anguilla. We have partnered with the Biodiversity Research Institute to help us process the samples for mercury content. This new data will be taken and correlated with similar experimental research that tested for local mercury levels in and around the Caribbean islands. It is hypothesized that mercury content levels in local seafood populations of Anguilla is within relatively safe limits for prolonged ingestion with no potential correlation towards mercury related diseases or long-term health complications.

\section{METHODS}

In this cross-sectional study, we partnered with the Biodiversity Research Institute that processed our samples and relayed the measurement findings of mercury content to us. The fish samples were purchased from local vendors that catch the various fish species daily around the island. The fishermen caught the fish close to shore and the acquisition of them is not considered deep sea fishing, hence they never stray more than 20 miles from the shore of Anguilla. The species we sampled included: Mahi mahi, Yellow Tail Snapper, Red Hind, Red Snapper, Doctor Fish, Grunt, Triggerfish, and White Back Bar Jack with a sample size of ten per species of fish, with the exception of Mahi mahi and Grunt that only had sample sizes of one and two respectively, due to a lack of catches by the fishermen.

The tissue samples were documented for weight and length. Then prepared as a $9 \times 5 \mathrm{~cm}$, filet sized, section from 
the specimen using a stainless-steel blade. The samples underwent temporary preservation by wrapping in clean, restaurant grade plastic wrap, placed in a zip-lock bag and frozen immediately. ${ }^{11}$ Once all the samples were collected, they were packaged with the appropriate amount of ice packs and sent to the Biodiversity Research Institute where the data was processed.

The data was processed at the Biodiversity Research Institute Toxicology Laboratory using their Milestone's DMA 80.12 The method detection limit (MDL) for the Biodiversity Toxicology Lab is $0.001 \mathrm{ppm}$. Results that fall under the MDL will be reported as such. ${ }^{13}$

\section{RESULTS}

Each of the sixty-three fish were weighed in ounces and measured lengthwise in inches. After measurements were recorded, a credit card size fish filet was prepared. After being shipped to the Biodiversity Research Institute in Maine, the samples were then weighed in grams.

\begin{tabular}{|ccc|}
\hline Fish Species & Number of Fish & Average THg (mg / Kg) \\
\hline Red Snapper & 10 & 0.1402 \\
Yellow Tail & 10 & 0.081 \\
White Back & 10 & 0.1274 \\
Red Hind & 10 & 0.2604 \\
Trigger Fish & 10 & 0.1611 \\
Doctor Fish & 10 & 0.0064 \\
Mahi mahi & 1 & 0.023 \\
Grunt & 2 & 0.028 \\
\hline Table 1.1. Average Total Mercury (THg) Concentration in Various \\
\multicolumn{2}{c}{ Fish Species in Anguilla } \\
\hline
\end{tabular}

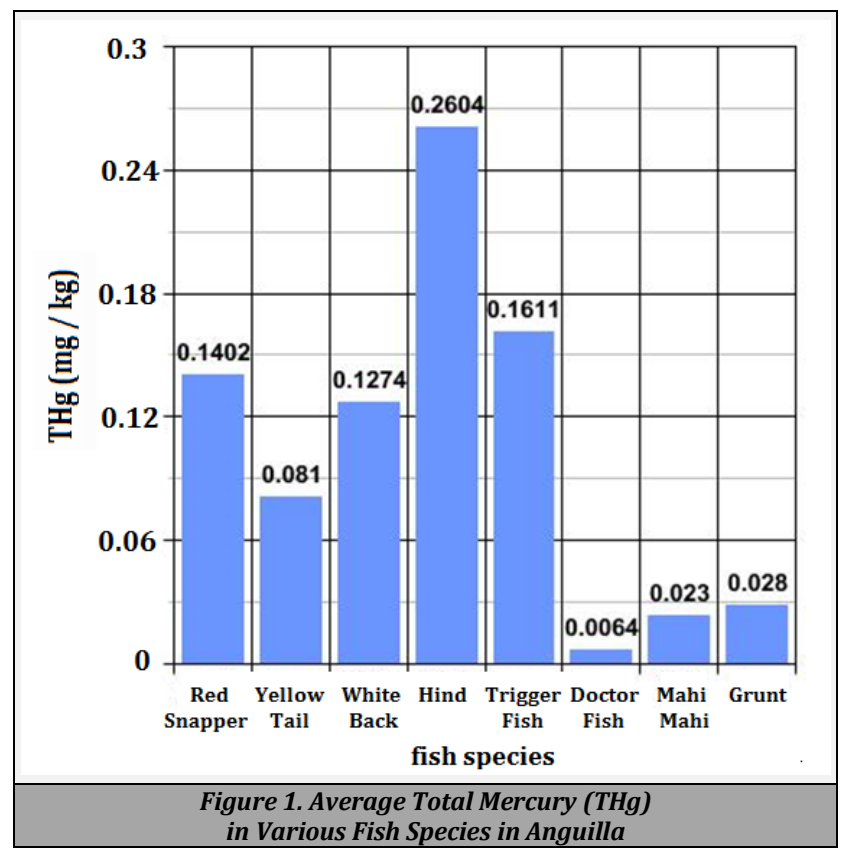

\begin{tabular}{|cc|}
\hline Mean & 0.1034 \\
Median & 0.1140 \\
\hline Interquartile Range (IQR) & 0.12135 \\
\hline Table 1.2. Mean, Median, and Interquartile Range for All Fish \\
Recorded in Milligrams / Kilogram $(\mathbf{m g} / \mathrm{Kg})$ \\
\hline
\end{tabular}

The total mercury concentration (THg) was measured using a mercury analyser and recorded in milligrams per kilogram (mg / Kg). The species being evaluated were: Red
Snapper, Yellow Tail Snapper, White Back Bar Jack, Red Hind, Trigger Fish, Doctor Fish (Blue Tang), Grunt, and Mahi mahi. Red Hind, which is a member of the Bass family, yielded the highest total mercury average with $0.2604 \mathrm{mg} / \mathrm{Kg}$. Trigger fish contained the second highest total mercury average of $0.1611 \mathrm{mg} / \mathrm{Kg}$. Red Snapper was the third highest with an average total mercury concentration of $0.1402 \mathrm{mg} / \mathrm{Kg}$.

\begin{tabular}{|ccc|}
\hline Fish Species & Median & Interquartile Range (IQR) \\
Red Snapper & 0.1039 & 0.09585 \\
Yellow Tail & 0.0606 & 0.090575 \\
White Back & 0.1288 & 0.035525 \\
Hind & 0.2423 & 0.1302 \\
Trigger Fish & 0.1778 & 0.082025 \\
Doctor Fish & 0.0059 & 0.002575 \\
Mahi mahi & 0.0387 & 0 \\
Grunt & 0.0560 & 0 \\
\hline Table 1.3. Median and Interquartile Range for Individual Fish \\
Species Recorded in Milligrams / Kilogram (mg / Kg) \\
\hline
\end{tabular}

The White Back Bar Jack was fourth highest with the average total mercury concentration at $0.1274 \mathrm{mg} / \mathrm{Kg}$. The second lowest species was the Yellow Tail Snapper with an average total mercury concentration of $0.081 \mathrm{mg} / \mathrm{Kg}$. The lowest species was the Doctor Fish, a type of Blue Tang, contained an average total mercury concentration of 0.0064 $\mathrm{mg} / \mathrm{Kg}$. Mahi mahi and Grunt were two species that were not a popular catch at the time of this project, and only one Mahi mahi and two Grunt were included in this study for comparison purposes.

Mahi mahi recorded a total mercury concentration of $0.0230 \mathrm{mg} / \mathrm{Kg}$ and Grunt had an average total mercury concentration of $0.0280 \mathrm{mg} / \mathrm{Kg}$. The Mean recorded was $0.1034 \mathrm{mg} / \mathrm{Kg}$. The Median was $0.1140 \mathrm{~mm} / \mathrm{Kg}$ and the IQR was $0.12135 \mathrm{mg} / \mathrm{Kg}$.

\section{DISCUSSION}

Fish are critical components for a well-rounded and healthy diet. Fish ingestion can be beneficial for women during pregnancy because they contain large quantities of $\omega-3$ polyunsaturated fatty acids that are not typically found in other food groups. ${ }^{14}$ Unfortunately a consequence of fish consumption during pregnancy is that certain species containing methylmercury pose a risk of exposure to a teratogen which is shown to have adverse developmental effects on an unborn child.15,16 This study suggests that species of fish, around the Caribbean island of Anguilla, containing high levels of methyl mercury $(>0.08 \mathrm{mg} / \mathrm{Kg}$ ), which includes the Red Hind (0.2604 mg / Kg), Trigger Fish (0.1611 mg / Kg), Red Snapper (0.1402 mg / Kg), White Back Bar Jack (0.1274 $\mathrm{mg} / \mathrm{Kg}$ ), and lastly, the Yellow Tail Snapper (0.081 mg / Kg) should be limited in the diets of all fish consumers, especially women who are in childbearing age (16 yrs. - 49 yrs.), pregnant or breastfeeding, and young children. ${ }^{17}$

Mercury toxicity poses a particular threat not only to early childhood development but also to in-utero development. The U.S. Environmental Protection Agency (EPA) reported that foetuses of pregnant women are said to be at an increased risk for mercury poisoning due to methylmercury being able to cross the placenta and disrupt the normal development of cognitive thinking, language, memory, and fine motor skills. ${ }^{3}$ 
Additionally, methyl mercury should be limited in young children due to organs not fully developed. According to the WHO's International Programme of Chemical Safety, it has been shown that amongst several standard fishing colonies, between 1.5 / 1000 and 17 / 1000 adolescence presented with adverse cognitive impairments caused by the ingestion of fish with elevated mercury concentrations. ${ }^{18}$ Therefore, it is pertinent that pregnant women, around the Caribbean island of Anguilla, should limit their intake of Red Hind, Trigger Fish, Red Snapper, White Back Bar Jack, and lastly, the Yellow Tail Snapper. Similarly, parents need to use caution with said species in the diets of young children.

Previous research performed by Saint James School of Medicine students assessed methylmercury concentration in six fish species caught around Anguilla in 2013 - 2014. They reported mercury concentrations of Mahi mahi $(0.08 \mathrm{mg} / \mathrm{Kg})$, Red Hind (0.07 mg / Kg), Tuna (0.04 mg / Kg), Red Snapper (0.03 mg / Kg), Blue Tang (0.02 mg / Kg), and Long Jaw Squirrel Fish $(0.03 \mathrm{mg} / \mathrm{Kg}$ ). Upon comparison between the 2013 - 2014 study (former) and the current study (latter), there has been an increase in methylmercury levels, most notably in the Red Snapper $(0.03 \mathrm{mg} / \mathrm{Kg} \rightarrow 0.1402 \mathrm{mg} / \mathrm{Kg}$ ) and the Red Hind $(0.07 \mathrm{mg} / \mathrm{Kg} \rightarrow 0.2604 \mathrm{mg} / \mathrm{Kg}$ ). When one takes into account the yearly recommendations of $1.6 \mathrm{ug} / \mathrm{Kg}$ of bodyweight of pregnant women per week per WHO 5 and the increased concentrations of methylmercury around Anguilla in these two species, Red Hind ( $272 \%$ per 6 years) and the Red Snapper (367 \% per 6 years), pose an increased risk to the fish consumers residing in Anguilla.

Although this study on methylmercury shows promise, there were a few limitations worth mentioning. Firstly, the study attempted to analyse the most popular fish species consumed in and around Anguilla to assess for methylmercury concentration. When one considers that there are approximately 12,046 marine species reported in the Caribbean region, it is difficult to assume the methylmercury concentrations in eight species is an accurate representation of the population. Secondly, the study's sample size $(X=63)$ was small and should be increased if the study were to be repeated. Thirdly, each of the sixty-three fish were weighed in ounces using a digital scale and measured lengthwise in inches using a measuring tape. Individual fish weight and length could vary depending on human interpretation.

\section{CONCLUSIONS}

Our findings support the notion that mercury concentrations within the tissues of fish around the Caribbean island of Anguilla have increased. Further research should be conducted to determine methylmercury concentrations in and around the Caribbean island of Anguilla to determine as to whether or not the results from this study accurately portray a population rise in toxic methylmercury levels in fish, as to whether the rise in toxic methylmercury concentration has had an impact on pregnant women living in Anguilla who regularly consume species with high mercury concentration, and as to whether there has been an increase in the number of Anguilla's miscarriage, in-utero complications, and abnormal foetus development over the past six years, as previous research ${ }^{1,3}$ suggests a link between consumption of methyl mercury concentrations and in-utero and early childhood developmental issues.

Data sharing statement provided by the authors is available with the full text of this article at jemds.com.

Financial or other competing interests: None.

Disclosure forms provided by the authors are available with the full text of this article at jemds.com.

We would like to thank the Biodiversity Research Institute, Portland, United States, for processing our fish samples for mercury analysis. Dr. Kallol Guha, CEO and President, Dr. Ravinder Kenue, Executive Dean, Dr. Claude Bernard Iliou, Dean of Basic Sciences, Dr. Ievgen Chebotarov and Dr. Alisa Chebatarova, Associate Professors for their support during this research project.

\section{REFERENCES}

[1] Mercury and health. WHO

2020. https://www.who.int/news-room/factsheets/detail/mercury -and-health

[2] Mercury resources. Department of Environmental Conservation. Dec.vermont.gov. 2020. https://dec.vermont.gov/wastemanagement/solid/productstewardship/mercury/resources

[3] Hong YS, Kim YM, Lee KE. Methylmercury exposure and health effects. J Prev Med Public Health 2012;45(6):35363.

[4] Office of dietary supplements - omega-3 fatty acids. Ods.od.nih.gov. 2020. https://ods.od.nih.gov/factsheets/Omega3FattyAcidsConsumer/

[5] Cai Y, Rooker JR, Gill G, et al. Bioaccumulation of mercury in pelagic fishes from the northern Gulf of Mexico. Can J Fish Aquat Sci 2007;64(3):458-69.

[6] Ahmad NI, Noh MFM, Mahiyuddin WRW, et al. Mercury levels of marine fish commonly consumed in Peninsular Malaysia. Environ Sci Pollut Res Int 2015;22(5):3672-86.

[7] News Update: U.S. per capita seafood consumption up in 2017 Seafood Nutrition Partnership. Seafood Nutrition Partnership.

2020.

https://www.seafoodnutrition.org/seafood101/news/news-update-u-s-per-capita-seafoodconsumption-up-in-2017/

[8] Consumption of fish and shellfish and the regional markets. Fao.org. 2020. http://www.fao.org /3/t8365e/t8365e04.htm

[9] Borash J, Davidson B, DiGregorio M, et al. The assessment of mercury contamination in Anguillan Fish. Saint James School of Medicine. 2014-2015.

[10] Consumption of fish and shellfish and the regional markets. Fao.org. 2020 [cited 2 April 2020]. http://www.fao.org /3/t8365e/t8365e04.htm

[11] Pennsylvania Department of Environmental Protection. Fish Tissue Sampling and Assessment Protocol. 2002.

[12] DMA - 80 Direct Mercury Analysis System - Milestone Milestonesrl.com. 2020 [cited 3 April 2020]. https://www.milestonesrl.com/products/mercurydetermination/dma-80-evo 
[13] Biodiversity Research Institution, BRI Science Communications. 2018. Mercury Biomonitoring in the Caribbean Region, Portland, ME. 2018-2019.

[14] U.S. Food and Drug Administration. Advice about eating fish - for women who are or might become pregnant, breastfeeding mothers and young children. 7-2-2019. https://www.fda.gov/food/consumers/advice-abouteating-fish

[15] Harada M. Congenital Minamata disease: intrauterine methylmercury poisoning. Teratology 1978;18(2):285-8.
[16] Costa LG. Contaminants in fish: risk-benefit considerations. Arh Htg Rada Toksikol 2007;58(3):367374.

[17] Koren G, Bend JR. Fish consumption in pregnancy and fetal risks of methyl mercury toxicity. Canadian Family Physicians 2010;56(10):1001-2.

[18] World Health Organization. Internationale Program on Chemical Safety - Mercury. 2020. https://www.who.int/ipcs/assessment/public_health/ mercury/en/ 